I might tell of other hindrances to recovery from the operation for hernia ; but I limit myself to those of inflammation of the testicle, of sloughing of the scrotum, and others which I have been able to study practically, and I pass the others by, as I have done many otherthings, especially the complications of herniæ with various local diseases, such as hydrocele, varicocele, undescended testicle, and others. I have seen only one or two cases of each, and can tell nothing which is not already well told about them. Indeed, for a conclusion, I must say that, though to some of you it may have seemed excessive to give four lectures on strangulated hernia, I have treated the subject very superficially, very incompletely. One lifetime is not nearly enough for its complete personal study, in even so large a field as this hospital supplies.

\section{ABSTRACT OF LECTURES}

\section{SURGICAL TREATMENT OF ANEURISM IN ITS VARIOUS FORMS.}

Delivered before the Royal College of Surgeons of England.

BY T. HOLMES, F.R.C.S., Professor of Pathology and Surgery.

LECTURE III.-Fune 7 th, 1872.

THE review of the table of cases in which the distal operation has been practised for thoracic aneurism was concluded. In seven cases, the left carotid has been tied for disease known to affect the arch of the aorta, and the operation has proved beneficial in all except one, in which the patient died from the direct effects of the ligature. One case was especially referred to, now under the care of Dr. Cockle, in which the carotid artery was tied by Mr. Heath in February last, and the patient was shown after the lecture to those present. The growth of the aneurism has been materially checked, and the patient is now in perfect health and able to walk fourteen miles without fatigue. The table of cases concluded with two of distal ligature of the third part of the subclavian for innominate aneurism, by Wardrop and Broca, in both of which also the operation was beneficial. The following conclusions appear to be those justified by present experience on the subject of Brasdor's operation on innominate aneurism. I. The distal ligature of the carotid alone, or in conjunction with that of the third part of the subclavian, cannot be trusted to produce the complete consolidation of the tumour. 2. The natural effect of the ligature of the carotid artery is to produce coagulation in the part of the sac directly connected with the mouth of that artery. 3. This may suffice, practically, for the cure of the aneurism when the subclavian portion of the sac is small, and shows no disposition to grow. 4. In other cases where the mouth of the subclavian is previously obliterated by impacted clot, the ligature of the carotid alone may effect a radical cure. 5. For these reasons it is better, in any case which appears to require distal ligature, to commence with the operation on the carotid alone, and afterwards to consider the propriety of securing the subclavian in either its first or its third part.

The question of the justifiability of operating on the first part of the subclavian was then considered. The operation has always hitherto failed from secondary hæmorrhage, and the possibility of repeating it justifiably depends on the possibility of obliterating an artery without dividing it. A historical summary was given of the attempts made with this view by John Hunter, Cline, and others, in the early days of the ligature; by Sir Philip Crampton, Mr. Porter, and others, with the presse-artère, acupressure, etc., and with the silver ligature : and it was shown that, although occasionally successful, these methods had not hitherto proved trustworthy. The history of the catgut ligature was then traced from its introduction by Sir Astley Cooper. Porta's experiments and operations were referred to ; and the experience lately acquired with the carbolised catgut ligature was related. A preparation was shown in which Mr. Holmes had tied the carotid and subclavian arteries in the human subject with this substance; the patient having died from another cause about nine weeks after operation. Both arteries were undivided; the subclavian permanently closed by organised tissue ; the carotid obstructed by clot. The collateral circulation during life had hardly been developed to so great an extent as usual; the pulse being only very faintly perceptible in either the radial or the temporal, thus showing that the trunks were really obliterated. This case furnished anatomical demonstration of the possibility of tying arteries without subsequent ulceration, the material of the ligature being subsequently absorbed. The reason for the failure of catgut ligatures in the hands of the older surgeons appears to be, that the wounds were not treated so as to produce rapid consolidation of their deep parts, and possibly the ligatures were not properly prepared. If subsequent experience prove it to be generally possible to secure this result of tying an artery, it might be justifiable to operate distally on the first part of the subclavian artery, though the chance of finding it diseased would render the operation very dangerous. Reference was made to the uncertainty of diagnosis between innominate and aortic aneurisms; and it was suggested that the indications for operation in cases of supposed innominate aneurism should be drawn from the progress of the case-that is, from the apparent extension of the sac up the course of the carotid artery and towards the trachea. With respect to ligature of the left carotid for aortic aneurism, it appears also to be beneficial in the same way - that is, by obliterating the carotid and the portion of the sac through which the stream passed into the carotid.

The next subject treated of was galvano-puncture, and it was shown that by the galvanic current clots of more or less solidity could be formed in an aneurismal sac. It was also shown, by reference to a case of subclavian aneurism under the care of $M$. Abeille, that these coagula may ultimately attain sufficient firmness to obliterate the aneurismal sac. At the same time it must be allowed that such coagula. are frequently not stable, but soften and meit down again into the blood-stream, thus rendering the operation nugatory. Further experience is required on many of the most essential details of this method ; and these ambiguities and uncertainties form a valid ground for rejecting the operation-at least for the present-in any case in which the artery is fairly accessible above the tumour.

\section{ON SOME ABNORMAL CONDITIONS OF THE} LIVER, ACCOMPANIED BY JAUNDICE.*

By EDWARD LONG FOX, M.D., Physician to the Bristol Royal Infirmary, Clifton.

THE cases referred to in this paper were not all due to one and the same condition of liver, but they were examples of peculiarities which are either unusual or obscure.

CASE 1. - A man, aged 50, was a patient in the Bristol Royal Infirmary, under Dr. Brittan (by whose courtesy I am allowed to mention the case here). He had only been ill for seven weeks, with intense jaundice, and the troublesome itching consequent on the jaundice. He had had hæmorrhage from various surfaces, and had passed blood per anum. The liver during life was seen to be much enlarged, but was smooth. At the necropsy, the heart was found to be fatty. The lungs were healthy. There was a little recent inflammation of the lower portions of the right pleura. The liver was very large; the ducts were much dilated all through the organ. The gall-bladder was enormously larye, full of black bile. The ductus choledochus was very large down to within half an inch of what should have been its entrance into the duodenum. Here it was entirely blocked, not with gall-stones, nor with any thickened secretion, but apparently as the result of inflammatory thickening. What should have been the duct was transformed into fibroid tissue, and could never have again become patent. The pressure of the occluded bile had very nearly produced an artificial opening into the duodenum lower down. The spleen was rather large. The mucous membrane of the small intestine through its whole extent was covered with blood. The kidneys were much tinged with biliary pigment.

CASE II. - A gentleman, aged 63, was first seen in May, $1870 . \mathrm{He}$ had been ailing for two months previously, and had complained of constant slight pain in the right hypochondrium. About five or six weeks previously he became suddenly jaundiced, and was very actively treated with calomel and podophyllin. In the first week of his illness, he once passed bile per anum, never since. He was always a spare man, but rapidly emaciated. He had lately been taking Turkish baths. Twenty years ago, he passed some gall-stones, but without pain and without jaundice. No tumour could be felt. There were some tension and tenderness over the head of the right rectus abdominis, especially on deep pressure. There were no ascites. He had intense jaundice. The bowels were confined. A little albumen was present in the urine. Sir William Jenner came down to see him, and gave as his opinion that the disease was probably a cancerous gland pressing upon the common duct, but that it was possible that the patient was suffering from a thickening, and a remediable thickening, of the duct itself. He suffered terribly from the icteric itching of the skin, and sank rather suddenly about a month after first coming under my observation. Death was preceded by twelve hours of coma. No post mortem examination was allowed. 
CASE III. - Last autumn I saw in Monmouthshire, with my friend Mr. Essex, a gentleman, aged about 70 , who was intensely jaundiced, and in whom, although the liver was large, there were no irregularities on the anterior surface. He would take no remedies, and sank rapidly. His death was doubtless hastened by constant vomiting, and he had some slight hxmatemesis. No post mortem examination was allowed. My opinion was that he was suffering from thickening of the duct, and not from cancer.

CASE IV. - A surgeon aged 70, who had been doing a large country practice for many years, was first seen in the autumn of 1870 , at his own house some miles from Bristol. He had been ailing for ten months, and had been jaundiced for the last six months of the time. His state at the date of my visit was one of great mental and bodily depression, and he was much emaciated. The left lobe of the liver was enlarged, but smooth. There was no pain or tenderness. The itching of the skin was terrible. A very little bile had been passed at stool on several occasions during his illness. $\mathrm{He}$ answered questions pretty well, but wandered slightly at times. The diagnosis lay between cancer of the lower surface of the liver and a remediable thickening of the duct itself. Having regard to the latter possibility, he took iodide of potassium, and pills containing blue pill, belladonna, and taraxacum. Six months afterwards he paid me a visit at Clifton, looking ten years younger, and perfectly well.

These four cases illustrate to my mind this somewhat unusual condition, subinflammatory thickening of the duct itself. The diagnosis between this affection and cancer of the lower portion of the liver is very obscure and difficult. I think that in this condition the jaundice is more sudden, the icteric itching more intense, the emaciation more rapid, the tendency to cerebral symptoms greater than in cancer, whilst the pain or tenderness over the region of the liver is generally less. But either may cause death, either may lead to congestion of the portal vessels, and as a consequence of this to hremorrhage into the stomach or intestinal canal, rather than to ascites. Three out of these four patients were very sober men, and of the fourth I have no record.

I believe it to be especially a disease of advancing age, and to bear the same relation to the catarrh of the duct often met with in the jaundice of childhood, that fibroid induration of the lung bears to catarrh of the bronchi and air-cells.

CASE v.-A lady, aged 26 , having suffered all the winter and spring from debility and loss of appetite, came under medical notice in May, I 87 I. In spite of having felt unwell for many weeks, she had carried on the ordinary duties of her life, in which was included the going up and down a steep hill several times a day to services at church. At the first visit, she seemed to be suffering from ordinary jaundice, dependent on catarrh of the ducts. The liver was slightly enlarged and a little painful. She had vomiting, constipation, intense jaundice, entire absence of colour in the motions, and a very deep-coloured urine. She was decidedly weak, and not in a condition to bear much medicine. Under small doses of aloes and colocynth, the colour reappeared in the stools in the course of ten days. She did not convalesce thoroughly as to strength, and what little power she had was again injudiciously used in long church services. About the middle of July, she had an attack of jaundice again, and then was so weak that it seemed impossible to give any aperient medicine. She became greatly emaciated, unable to sit up ; having some cough, and a little consolidation at the apex of the right lung. There was complete anorexia. The urine was of a very deep colour.

My friends, Br. Beddoe and Dr. Fripp, who kindly gave me the advantage of their help, believed, as I did myself, that she was the subject of chronic atrophy of the liver ; the more so, as the slight enlargement of the liver that existed in May had now given place to an ab. normally decreased area of hepatic dulness. Still, however, she had no ascites, and no nerve-phenomena ; nor was leucine or tyrosine found in the urine. The jaundice persisted for six weeks. She was taken into the country to satisfy a craving desire on her part ; and during a portion of August and September she was carried from her bed to a sofa out of doors. The menstrual function ceased in August. 'Towards the middle of September, the bile was no longer excreted at all, the urine regained its normal colour, the skin lost the jaundiced hue, the freces were perfectly white, whilst the general condition remained much the same. This complete abeyance of all hepatic function persisted for about seven weeks, whilst her pulse was always 120 , her appetite very poor; the power of sitting upright, without feeling very faint, impossible. I need not say that the prognosis was as bad as possible. In the second week of November, the liver quite suddenly began to secrete bile arain; a certain amount of appetite returned, and enough strength to enable her to drive out and to take short walks. In December, the menstrual function was regained. This improve- ment has steadily increased; and the young lady, though still rather weak, is convalescent.

The difficult point in this case is, of course, the fact of the liver resuming its action after seven weeks of complete inactivity ; but in connection with the progress of the case are the interesting points of en. tire freedom from cerebral symptoms during the period of suppression, and the fact that digestion, sufficient to support life, went on without the help of the bile.

CASE VI.-A young lady, aged 2I, had been ill for a week when first seen in December I870. She was then deeply jaundiced, with some hepatic enlargement and tenderness, with high coloured urine and pale stools. On the third day of jaundice she fell into a state of torpor, and exhibited great moroseness on being roused. She did not know the people about her, and lay comatose if left alone, and with very dilated pupils. My friend Mr. Bryant and I spent much time with her, using calomel and castor-oil, enemata, and blisters to the neck and over the right hypochondrium. The temperature was normal throughout. The next day she had torpor, but was exceedingly morose ; but on the 23 rd, after these cerebral symptoms had persisted more or less for four days, she became perfectly rational, whilst no bile appeared

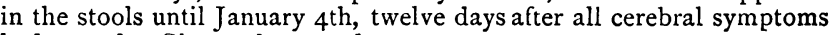
had ceased. She made a good recovery.

One more point in connection with these cases of jaundice. Case II died in the summer of 1870 . Case vI was taken ill in the same village in December of the same year. She was his niece, and had seen him often during his illness. During her convalescence, her sister sickened and had a troublesome attack of jaundice. This sister, during her convalescence, went to the seaside to stay with her cousins, the daughters of Case II. Soon after her arrival, one of them, a married cousin, had jaundice there, then a sister (Case v), also a daughter of Case II. During the convalescence of Case $\mathrm{v}$, another of her sisters had a sharp attack of jaundice; and immediately afterwards another cousin, of a different family, who had seen something of them during their illness, also had an attack.

I have no hesitation in stating my conviction that the occurrence of jaundice in these ladies, one after another, was purely accidental ; but I am not surprised to find that their friends are looking upon this symptom as a highly contagious disease. The fact is only mentioned here as an illustration of the looseness with which the spread of disease by contagion is often spoken of.

\section{NOTES OF A FATAL CASE OF HYSTERIA.*}

\section{By ROBERT W. FOSS, M.D., Stockton-on-Tees.}

ABOUT three o'clock in the afternoon of October IIth, I870, as I was passing his house, I was called in by B. to see his daughter, aged 19, who, he informed me, had been in convulsions ail day. When I saw her she was perfectly conscious, throwing her arms and legs about, laughing and crying alternately, in fact, having hysterical convulsions. She complained of pain in the right side of her head, also of the globus hystericus rising up from her abdomen to her right chest, where it stopped. Her chest was normal both to percussion and auscultation. Pulse about 8o, small. She also stated that she had had leucorrhœa, with much offensive discharge, for the last fourteen months, and since that time had had these hysterical attacks. She had been under medical care all this time, and was for some months a patient in an in. firmary. Her father stated to me that all the medical men who had seen her said that she was simply suffering from hysteria with leucor. rhœa, and that in time would be well again. I expressed a similar opinion, believing that it was a case more for moral than medical treatment. Within three hours of this she was dead, having expired in one of these paroxysms. Ier father was anxious that the real cause of his daughter's death should be discovered, therefore Mr. A. E. H. Trotter and myself, assisted by Mr. Ruck, next day made a post mortem examination of her body.

The right lung was normal, as was also the left, with the exception of some slight hypostatic congestion at the base. There was some frothy mucus in the bronchial tubes. There were no pleuritic adhesions. The heart was pale in colour, and rather flabby. There was a small clot of blood at the apex of the right ventricle; the other cavities were empty. The liver, which seemed rather larger than usual, on section, was normal, as were also the kidneys and suprarenal capsules. The contents of the cranium appeared perfectly natural. The base of the uterus was concested, and its walls were thicker than usual. The mucous membrane lining the interior was covered with a thick 